\title{
Smoking and Health
}

\section{Policies and postures in smoking control}

\author{
L MARKS
}

\begin{abstract}
"It is also a responsibility of the society to create, by legislation and other activities, such a social climate that encourages health promoting rather than health impairing conditions."

VALFRID PAULSSON, chairman, Swedish National Smoking and Health Association.
\end{abstract}

The importance of creating a social environment which discourages the use of tobacco has been emphasised by a wide range of national and international health and other associations. ${ }^{1-4}$ Recommended measures include prohibiting all tobacco promotion, adopting effective health warnings, protecting the non-smoker, controlling appropriate emission products of cigarettes, increasing prices, controlling sales outlets, and banning sales to the young. Clearly a wide-and in some cases widening - gap exists between such recommendations and their translation into policy.

This paper reviews measures adopted for the control of smoking in 15 nations in the Organisation for Economic Cooperation and Development (OECD) and updates earlier reviews. ${ }^{2}{ }^{5}$ It forms part of a wider study both of the processes of policy formation and of the complex relations between policy measures and changing trends in consumption. The following countries were chosen on the basis of economic comparability with the UK - that is, a gross national product of at least $\$ 5000$ per head in 1978: Australia, Austria, Belgium, Canada, Denmark, Finland, France, Japan, The Netherlands, New Zealand, Norway, Sweden, USA, and West Germany. (Switzerland, Iceland, and Luxemburg were excluded because satisfactory data were not available.)

None of these countries lacks anti-smoking measures. The range is wide, however. At one extreme is extensive legislation consistently and strictly enforced; at the other are voluntary

Unit for the Study of Health Policy, Department of Community Medicine, Guy's Hospital Medical School, London SE1 1YR L MARKS, BA, MSC, research assistant agreements with the tobacco industry, restricted in scope and feebly implemented. In between lies a medley of fragmented legislative action, voluntary codes of agreement, local regulations, and the activities of government and non-government organisations and health education groups, each country evolving its own blend. Simple categorisation of countries in terms of the strength of their policies and regulatory measures is therefore less than straightforward. This paper focuses on legal and other constraints on the smoking and promotion of tobacco. A comprehensive, health-orientated tobacco policy would include other measures such as the control of tobacco production and processing and health education.

\section{Background}

Despite major differences in the extent of policy adoption and implementation, certain policy measures are common to most of the countries under review. The three most commonly adopted are bans on the advertising of cigarettes on TV and radio, the publication of health warnings on cigarette packets and advertisements, and restrictions on what is generally (if dubiously) termed the "creative content" of tobacco advertising. Most recent are attempts to protect the nonsmoker through banning smoking in specified public places. Fiscal measures, too, are widespread, but with some exceptions-for example, Denis Healey's supplementary $\operatorname{tar} \operatorname{tax}$ (1978-81) applying to all cigarettes yielding $20 \mathrm{mg}$ tar or more-they are ambiguous as health policy measures.

Health warnings were generally adopted-often through legislation -in the 1970s, and, of the 15 countries under review, Denmark seems to be the only one which has not yet adopted this measure. The USA was a pioneer, passing legislation in 1965 due to action by the Federal Trade Commission. ${ }^{6}$ Somewhat slower off the mark was West Germany, where warnings have appeared on advertisements only since February 1981 (and on packets from October 1981). In common with New Zealand, Canada, and the UK, West Germany negotiated its warnings through voluntary agreements with the tobacco industry. The Netherlands has just passed legislation to ensure that warnings will be fully implemented from March 1982-a full 16 years after the USA. 
It was also mainly in the 1970s that those countries where advertising appears on radio and TV forbade the advertising of cigarettes through these channels. Some countries (such as Norway) have gone further, attempting to ensure that smoking appears as little as possible in programmes. New Zealand and the UK led the way, banning cigarette advertising on TV and radio in the 1960s. Japan appears to be the only country where this activity is still permitted, though this is now restricted to new brands.

Since the 1960s there have been restrictions on the content of cigarette advertising-for example, that it should neither appeal to the young nor claim health properties for cigarettes. Typically, where limitations on the scope and content of advertising form part of voluntary agreements with tobacco industries, a plethora of alternative and unregulated advertising strategies have been deployed, sports and arts sponsorship in the UK being two clear examples.

Bans on smoking in public places are not recent. Many originated as fire precautions and some, as in the Australian transport system, as a means of reducing cleaning costs. More recently, however, smoking in specified public places has been increasingly restricted to protect the health of the non-smoker. This has particularly been the case in Canada and the USA. Restrictions often take the form of bylaws (as in Toronto, Ottawa, or Halifax) or, in the USA, State laws (such as the Minnesota Clean Air Act, ${ }^{7}$ which is widely taken as representing the model of legislation on this problem). More than 30 States in the USA have now passed non-smokers' protection laws. ${ }^{8}$

These similarities should not be allowed to cloud the profoundly different approaches, priorities, and policies in the countries studied. From a policy perspective the major distinction lies between countries which have primarily adopted a legislative approach as part of a comprehensive smoking policy and those which have adopted a piecemeal approach based on voluntary agreements with the tobacco industry.

\section{Laws and agreements}

Many countries have enacted legislation in specific areas of tobacco policy. Such legislation may be primarily of historical interest, such as Canada's Tobacco Restraint Act 1908, which prohibits giving tobacco products to those under 16. (This act is generally accepted as unenforced and no health legislation on tobacco policy has been enacted since then.) Sales to minors have been banned in Norway since 1899, in New Zealand since 1927, and in England and Wales since 1933. In the UK the only major legislative defeat for the tobacco industry was the 1964 TV Act, which banned the advertising of cigarettes on TV and was passed after the industry had refused to restrict advertising to after $900 \mathrm{pm}$. Federal legislation in the USA is restricted to health warnings (1965) and TV and radio advertising. The only countries which have attempted a comprehensive legislative attack on the smoking problem are Finland and Norway and to a lesser extent Sweden, France, and Belgium.

Norway and Finland-Norway was the first of the 15 countries to adopt such an approach with the now famous Tobacco Act of 1973 (implemented in 1975). ${ }^{1011}$ This prohibited all promotion of tobacco and sales to minors and provided for health warnings and government control of tar, nicotine, and carbon monoxide levels. In Finland the Government-appointed Standing Committee on Smoking and Health concluded that a policy seriously aimed at reducing tobacco consumption could not be effectively pursued through the often-violated voluntary agreements. In 1976 a comprehensive Bill was unanimously approved, and the Finnish Tobacco Act came into force on $1 \mathrm{March}$ 1978. Unlike the Norwegian Tobacco Act, it included a ban on smoking in public places, the general approach being that of "rule-switching" - that is, smoking in public places was prohibited unless specifically allowed. ${ }^{12}$ In each case legislation was seen as an essential part of the campaigns to reduce consumption. With the removal of advertising sponsorship, it is hoped that the young will grow up in an environment where smoking is not projected as a "normal" social activity.

The co-operation and co-ordination of different Government departments in both Norway and Finland played an essential part in the implementation of comprehensive tobacco policies.

France and Sweden-Less comprehensive in their scope were the laws passed in France in 1976 and Sweden in 1978. Both laws prohibit advertising, except in the press, although there are some limitations on expenditure and space devoted to press advertising. The French law allows the sponsorship of sport involving certain motor vehicles only and bans smoking in public places unless adequate ventilation is provided. Both countries have undertaken extensive campaigns to coincide with legislative action. In France highly intensive campaigns have taken place every year since the passing of the act, whereas in
Sweden a longer-term strategy has been adopted and activities form $\underline{\square}$ part of a 25-year programme to produce a "smoke-free generation." $>$

Belgium and West Germany-Also adopting a legislative approach are those countries which possess empowering legislation in addition to $c$ voluntary agreements. The 1977 law in Belgium, designed to protect $\widehat{\widehat{\Omega}}$ the consumer where foodstuffs and other products, including tobacco, are concerned, has recently (March 1980) been used to extend the restrictions on tobacco advertising. In 1974 a law which allows for the restriction of advertising in the interests of consumer protection was passed in West Germany. ${ }^{13}$ Although this law confers the power to $\varrho$ impose health warnings, it took two years of wrangling with the tobacco industry before the text of the warning was finally agreed-voluntarily. $\overrightarrow{\bar{N}}$

\section{VOLUNTARY AGREEMENTS}

Voluntary agreements should be familiar to UK readers, as the principle of action based on such agreements with the tobacco com- $\omega$ panies is firmly entrenched in the policymaking repertoire of present $\overrightarrow{0}$ and past UK Governments. The same is true of Australia, USA, and Canada (except for British Columbia, which has legislation). These $\vec{\omega}$ countries have continued this tradition since voluntary agreements first became widespread in the 1960s. Typically, the agreements lack $\frac{0}{3}$ comprehensive monitoring or enforcement, penalties for infringements are rare, and loopholes abound. Codes of conduct vary greatly in $\propto$ scope and content. In the UK, for example, tobacco companies are still allowed to advertise on public transport, in cinemas (provided $\omega$ $\mathrm{X}$-rated films are showing), and on hoardings (though as a result of the $\vec{\omega}$ recent voluntary agreement from July 1981 advertising posters are not $\omega$ allowed on sites adjacent to schools and children's playgrounds). In Canada, another country which has proceeded almost exclusively via 음 voluntary codes, a ban on advertising near schools was agreed as early $\sigma$ as 1972. While Denmark, Austria, and The Netherlands do not have a T good track record in health warnings, in some respects their codes for $\mathbb{D}$ advertising are stricter than those of the UK. No advertising is allowed on public transport, for example. Neither Denmark nor New Zealand ${ }^{14}$ allows cigarette advertising on hoardings or in cinemas.

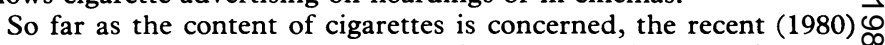
voluntary agreements in the UK included a provision to eliminate the advertising of cigarettes which contain $20 \mathrm{mg}$ or more of tar. Such an "advance" is put into perspective, however, by the fact that in Canada cigarettes which contain over $22 \mathrm{mg}$ of tar and $1.6 \mathrm{mg}$ of nicotine have not been on sale since 1972. Such an agreement would exclude all middle to high tar cigarettes sold in the UK. Although ֶू

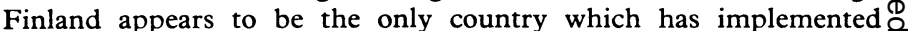
legislation controlling tar and nicotine levels ${ }^{15}{ }^{16}$ many countries, such $\overrightarrow{\vec{O}}$ as Canada, Austria, the USA, and France, now print tar, nicotine, and (in Sweden) carbon monoxide levels of packages instead of the more general classifications printed on cigarette packets sold in the UK.

It is difficult to generalise about the relative strength of voluntary agreements, not least because commentators from the different countries invariably emphasise the enormous difficulties in trying to en- force them-a factor which no doubt helps to explain why their use is 3 so favoured by the tobacco companies.

\section{Organisational activities}

Both the activities and the nature of organisations concerned with smoking are important not only for their influence on policy formation? but also for their potential for monitoring existing agreements, $N$ whether legislative or voluntary, and for publicising smoking issues. N In its 1975 report $^{17}$ the World Health Organisation recommended ${ }_{O}^{\omega}$ that, "Each government should establish an adequately financed central committee, or other appropriate body, to prepare, co-ordinate and supervise specific programmes for the control and prevention of cigarette smoking."

\section{GOVERNMENT BODIES}

Such advice has not been acted on universally. Neither Japan norס Denmark possesses such a body. Where anti-smoking activity is an priority in government health departments (as in Finland), the absence of such organisations need not prove a major drawback. In some countries, however, it is a part of government policy that well-staffed organisations are set up, devoted to preventing smoking. 
In 1965 the Federal Government of the USA created the National Clearinghouse for Smoking and Health (subsequently renamed the Office on Smoking and Health). Its funds have been severely cut back by the Reagan administration. It was formed to establish a national programme of public information, education, and research. Another American association (though non-governmental), the National Interagency Council on Smoking and Health, has a membership which includes no fewer than 35 national organisations.

Norway's National Council on Smoking and Health was set up by the Government in 1971. This body includes members with skills in medicine, social psychology, sociology, education, mass communication, and law. Its terms of reference are to "prepare, propose, coordinate, and supervise governmental measures against the harmful effects of smoking." It has a permanent staff of five-in a country of about four million people. In contrast, Action on Smoking and Health (ASH), the UK anti-smoking organisation set up in 1971 and largely funded by the Government, has only seven full-time staff for the population of England and Wales. This disparity in resources is heightened by the fact that, at the time of the Norwegian Tobacco Act, lung cancer rates in Norway were less than one-third of the rates in England and Wales.

As early as 1963-4, the Swedish Government's budget included a grant for a specialised agency on smoking and health. The size of this budget trebled from 1975 to 1978 . A final example is the Canadian Council on Smoking and Health (1974), which has as part of its brief, "The encouragement of governmental and social action to eliminate smoking." Although it is not a governmental association, the Government provided development funding for three years.

In addition to the formation of relevant organisations, many governments have produced or commissioned influential reports on smoking (Norway, USA, Austria, The Netherlands). In countries where there is no special statutory organisation, and where some government funds are set aside for anti-smoking activities, either health departments or health education councils undertake their organisation. The problem of smoking thus has to take its place among the myriad other claims on time and resources.

\section{MEDICAL ORGANISATIONS}

A wide range of medical organisations has also been concerned with the consequences of smoking. In the UK, for example, the Royal College of Physicians not only published three influential reports (in $1962,1971$, and 1977$)^{4}$ but was also responsible for setting up ASH in 1971. The associations concerned with specific diseases have been active in many countries. As early as 1969, the Finnish Cancer Society instigated an anti-smoking campaign and, more recently, the Australian anti-cancer societies have lobbied the Government on the prohibition of advertisements. Indeed, the legislation on the labelling of cigarette packets resulted largely from their efforts.

In other countries such societies have been less active. The National Commission on Smoking and Public Policy, set up by the American Cancer Society in 1976, pointed out that the involvement of the national disease associations in the campaign against cigarettes had been minimal. ${ }^{18}$ Likewise, the UK organisations (with the exception of the Ulster Cancer Foundation $)^{\mathbf{1 9}}$ and West German cancer societies have been criticised for a lack of involvement. Until very recently the American Medical Association had 1.4 million dollars of its pension fund invested in tobacco stocks. ${ }^{20}$

\section{NON-SMOKERS' RIGHTS, MOP UP, AND BUGA UP}

Other organisations have been formed to protect the rights of the non-smoker. Particularly in Canada and the USA these have undertaken powerful lobbying activities. In Canada, for example, there are autonomous non-smokers' organisations such as the Non-Smokers' Rights Association and a wealth of local groups. Their activities have resulted in important bylaws which have protected the non-smoker from the effects of passive smoking, by banning smoking in public places.

In the USA court cases seeking to defend the rights of non-smokers have been fought by ASH, a campaigning body. ${ }^{21}$ Since 1973 nearly 800 Bills restricting smoking have been introduced, and about 70 have become law. A recent report to the USA Tobacco Institute stated that the emergence of non-smokers' rights issues was "the most dangerous development to the viability of the tobacco industry that has yet occurred."22

Other more idiosyncratic groups have also been influential in modifying the practices of the tobacco companies. A recent example is the activity of the Australian Movement Opposed to the Promotion of Unhealthy Products (MOP UP). This group of health workers managed to get the largest tobacco advertising campaign in Australia modified by testing a clause in the advertising industry's voluntary code of self-regulation. ${ }^{23}$ This clause prohibited the use in cigarette advertisements of people who hold a major appeal for adolescents. In Australia, too, billboard advertising has come under (direct) attack from the aptly named BUGA UP (Billboards Utilising Graffitists Against Unhealthy Promotions).

\section{USING THE MEDIA}

The effectiveness of many of these groups and organisations derives not only from their direct influence on policymakers but also from their use of the media. Commentators from both Norway and Finland suggest that the extensive media coverage before and during the legislative process made a major contribution to the public debate and may well have influenced the subsequent consumption of cigarettes.

The effects of media coverage of epidemiological findings and of policy initiatives, whether national or from other countries, is a complex and important area of study as yet relatively unexplored. Unpublished research for the Bureau of Economics of the US Federal Trade Commission indicates, however, that each of three major reductions in per head consumption of cigarettes in the USA (in 1953, 1964, 1968-9) was preceded by the release of important information on the negative consequences of smoking.

The potential of the media for health education campaigns is perhaps most successfully exploited in countries such as Austria, where there is legislative provision for the TV and radio monopoly to support public health matters. In the extensive campaign carried out in Austria (1980-1) $85 \mathrm{TV}$ and 485 radio spots were provided free of charge in eight weeks - $£ 500000$ worth of time. Such campaigns are likely to be most effective where, as in the French campaigns, use of mass media is part of a wide-ranging strategy which includes legislative action.

\section{The other side of tobacco policies}

Owing to lack of enforcement policies which appear potentially effective may be little more than "paper tigers." Furthermore, they may reflect avoidance strategies by the tobacco industry under threat of more restrictive action or they provide hidden benefits for the industry.

\section{IMPLEMENTATION}

Clearly, policies risk the fate of not being implemented unless mechanisms for their enforcement are incorporated unambiguously in the formal policy statement and adequate resources are set aside for enforcement. Even then, the many gaps between the letter and the spirit are regularly exploited, and the law serves to challenge the imaginative powers and substantial resources of the tobacco companies.

Furthermore, some policies are difficult to enforce by their very nature-for example, the banning of smoking by minors. The existence of unsupervised vending machines turns a law which is difficult to enforce into one which cannot be enforced. Similarly, many of the bans on smoking in public places depend on voluntary compliance (though in the USA this may vary from State to State). Typically, where voluntary agreements exist penalties for infringement are rare. Indeed, in the UK, for example, there are no serious penalties.

\section{ADVERTISING RESTRICTIONS}

Advertising bans may serve to protect state monopolies from foreign competition, as in Italy. The control of advertising in one sector also often leads to its emergence or expansion in another. The banning of TV and radio advertising of cigarettes in the USA for example, led to increased advertising in the weekly news magazines. It has been convincingly argued that magazines play down the impact of tobacco on health because of their dependence on revenue from cigarette advertisements. ${ }^{24}$

The USA ban also resulted in the removal of the anti-smoking advertisements made compulsory by the Fairness Doctrine. This doctrine, applied by the Federal Communications Commission to 
cigarette commercials in 1967, required broadcasters to provide free time for the presentation of anti-smoking advertising, which was worth about $\$ 60 \mathrm{~m}$ in 1970 . Thus, one of the few measures believed to influence the consumption of cigarettes (anti-smoking advertisements) was dispensed with. ${ }^{25}$

In the UK the $1965 \mathrm{TV}$ ban led to the proliferation of gift coupon schemes. More recently, sponsorship of sport and the arts has provided an effective way of evading the spirit of the advertising restrictions. Such promotion also has the powerful effects of fostering financial dependence on the tobacco industry, legitimising its role, and increasing its prestige. Daube has argued (in a paper on obstacles to health promotion given in Peebles in November 1980) that TV coverage of tobacco-sponsored events has resulted in far more televised cigarette advertising than ever existed before the ban. Such activities highlight the lack of consistency between different government departments over smoking policy.

There are also many ways of bending advertising restrictions. In Australia, for example, broadcasting advertisements were finally eradicated by the Liberal Party (1975-6) after a loophole in the law had allowed tobacco companies to make corporate advertisements and advertise the company rather than the cigarettes.

Battles continue in France as the ingenuity of the tobacco industry results in increased package advertising or in pseudo-scientific articles on less harmful cigarettes which both pose as research and serve as publicity.

Rules which forbid advertising specifically designed to appeal to the young are regularly breached, through the use of sports stars or through advertisements in magazines which include a young readership.

\section{VOLUNTARY AGREEMENTS AND THE TOBACCO COMPANIES}

The history of voluntary agreements is very much one of how to get away with the least restrictive codes, and particularly of how to avoid legislation. One well-documented example of this is the Canadian Cigarette Advertising Code of January 1972. This was agreed by the Canadian Manufacturing Council to avoid the proposed ban on all cigarette advertising. ${ }^{26}$

Legislation may also provide hidden benefits for the companies. In the USA, for example, the Cigarette Labelling and Advertising Act of 1965 made the adoption of health warnings compulsory. It also, however, prohibited the Federal Trade Commission and other federal agencies from regulating cigarette advertising and nullified existing State and local advertising regulations.

\section{HEALTH WARNINGS}

Health warnings may serve to decrease the legal liability of the tobacco companies for individual deaths from cancer. As warnings typically lack "message efficiency" 27 in themselves they are probably not effective deterrents to smoking. Sweden has tried to overcome this problem through a rotating system of 16 different health warnings. ${ }^{28}$ Where health warnings are legislated into existence, as in Norway, Finland, and Sweden, they can be more easily amended, and the texts chosen and changed independently, so that the message may retain its freshness.

\section{LOW TAR CIGARETTES}

The importance of publicising low tar brands has often been used by the industry as an argument to justify continued advertising. ${ }^{29}$ Such advertising may also minimise anxieties about the risks of smoking and thus create a false sense of security. From a health perspective, however, the increasing popularity of low tar brands is a mixed blessing. While reducing the risk of lung cancer, the switch to lower tar cigarettes may also change smoking patterns as smokers try to maintain their nicotine levels. Such changes may include deeper inhalation, shorter butts, and increased consumption. ${ }^{30}$ This, in turn, may result in increased doses of carbon monoxide and of the cigarette additives which are increasingly used in tobacco processing and flavouring. ${ }^{31}$ In addition an ultra-low-yield cigarette does not produce ultra-lowyield sidestream smoke, so risks to the non-smoker are not necessarily reduced. ${ }^{32}$
TAXATION INCREASES

Consumption usually declines after a significant increase in the price of cigarettes, but higher prices often increase government dependence $c$ on taxation revenue and are rarely imposed purely on health grounds. $\widehat{C}$ It is also doubtful whether a health policy which primarily affects the economically disadvantaged because of the pattern of smoking (regressive taxation) should be wholeheartedly accepted as a wise public health measure. Increases in taxation also need to be set in the context of the comparative real prices of cigarettes. In 1979-80, for example, $\varrho$ Marlboro cigarettes cost over twice as much in Denmark and Sweden as in Canada or the USA (taking real purchasing power into account). $\overrightarrow{\vec{A}}$

Finland is the only country which uses a percentage of the revenue from tobacco taxes to finance measures to reduce tobacco consumption.

\section{Conclusions}

Many important developments in smoking policy have occur- $\vec{\circ}$ red since the early 1970s. Norway and Finland, in particular, $\stackrel{-}{\omega}$ have paved the way with comprehensive, health-oriented tobacco $\vec{\omega}$ policies which have thrown into relief the partial approach $\frac{\text { a }}{8}$ adopted by other countries. Canada and the USA have witnessed 3 the rapid growth and powerful lobbying activities of various non-smokers' rights movements. The relevance of such activi- $₫$ ties has been underlined by increasing evidence of the dangers of $\mathrm{\omega}_{\mathrm{G}}$ smoking to the non-smoker as well as to the smoker and of the $\vec{\omega}$ increasing cost of tobacco-related diseases to health services as $\dot{\omega}$ well as to individuals.

The reasons for the adoption (or non-adoption) of policies raise far larger issues ${ }^{33}{ }^{34}$ than those discussed here. The relative $\sigma$ strength of the tobacco industries and their role in the economic Th structure (from agricultural interests to shipping, marketing, $\frac{\mathbb{O}}{7}$ distribution, and manufacturing) have a major influence in the process of policy formation, as does the level of commitment of $\underset{\gtrless}{\gtrless}$ policymakers to overcoming the smoking problem. Further $\vec{\bullet}$ investigation and analysis is needed into the obstacles encountered by health-oriented groups in their attempts to get policies adopted and implemented, and the difficulties of such investigations should not be underestimated.

Further research is also needed into the combination of policies likely to be most effective in changing smoking be- $\frac{Q}{\varnothing}$

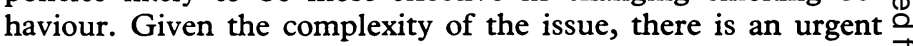
need for concise and comparative information which is easily $\overrightarrow{\overrightarrow{0}}$ available to policymakers. Collaboration by international 3 organisations is also important because of the transnational nature of the tobacco industry. The Food and Agriculture Organisation, for example, which is still promoting the cultivation of tobacco, ${ }^{45}$ needs to co-operate further with the World Health Organisation, which is attempting to influence policy-io makers to legislate and take other action against smoking. In 3 this way, what has been a predominantly anti-smoking policy $\delta$ may eventually be converted into a wider-ranging anti-tobacco policy.

I thank my colleagues at the Unit for the Study of Health Policy $N$ for their help and the many people who kindly provided data and $>$ commented on earlier versions of this paper.

\section{References}

1 Expert Committee. Controlling the smoking epidemic. WHO Tech Rep Ser $1979 ; 636$.

2 WHO. Legislative action to combat smoking around the world. International Digest of Health Legislation 1976;27:493-517.

${ }^{3}$ Gray N, Daube M, eds. Guidelines for smoking control. UICC Technical Report Series 1980;52:1-15.

4 Royal College of Physicians. Smoking or health. Tunbridge Wells: Pitman Medical, 1977. ${ }^{5}$ Moerloose J de. Legislative action to combat smoking around the world.

${ }^{6}$ US Public Health Service. Surgeon General's Advisory Committee on Smoking and Health. Smoking and health; report. Washington, DHEW

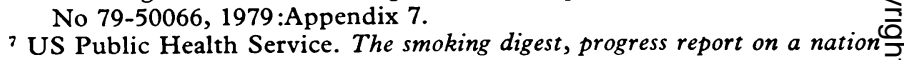
kicking the habit. Washington, DC: DHEW, 1977:90-1. 
${ }^{8}$ Austin WT, Gardner SW. Light up or butt out: an assessment of antismoking laws in the United States. Deviant Behaviour 1980;1:395-410.

9 US Public Health Service. State legislation on smoking and health. Atlanta: Centres for Disease Control. DHHS; Bureau of Health Education, yearly since 1975 .

10 International Digest of Health Legislation 1975;26:571-2.

11 Bjartveit K. The Norwegian Tobacco Act. Health Education fournal 1977; $36: 3-10$.

${ }^{12}$ Leppo K. Smoking control policy and legislation. $\mathrm{Br}$ Med $\mathcal{f} 1978$; : 345-7.

13 West German Department of Youth, Family and Health. Law of 15th August, 1974 for the Revision and Emendation of the Legislation on Trade in Foodstuffs, Tobacco Products, Cosmetics and other Commodities. International Digest of Health Legislation 1965;26:535-6.

14 Anonymous. Code for the marketing of cigarettes adopted in New Zealand. International Digest of Health Legislation 1980;31:973-7.

15 WHO. International Digest of Health Legislation 1977;28:491.

16 WHO. International Digest of Health Legislation 1980;31:307.

17 Expert Committee. Smoking and its effects on health. WHO Tech Rep Ser $1975 ; 568$

${ }^{18}$ Anonymous. National Commission blames Cancer Society. ASH Newsletter 1978;Jan/Feb.

19 Anonymous. Medical charities and prevention. $B r$ Med $\mathcal{f}$ 1979;ii:1610.

20 Anonymous. ASH Newsletter 1981 ;Nov.

${ }^{21}$ Sapolsky HM. The political obstacles to the control of cigarette smoking in the USA. Fournal of Health Politics, Policy and Law 1980;5:277-90.

${ }^{22}$ Roper Organization Incorporated. A study of public attitudes towards cigarette smoking and the tobacco industry in 1978. Vol 15. In: Federal Trade Commission. Report to Congress for the Year 1978. Washington, DC: US Govt Printing Office, 1978.
${ }^{23}$ Chapman S. A David and Goliath Story: tobacco advertising and selfregulation in Australia. $\mathrm{Br} \mathrm{Med} \mathcal{F} 1980 ; 281: 1187-90$.

${ }^{24}$ Whelan EW. Tobacco and editorial policy. F $A M A$ 1980;244:2045.

${ }^{25}$ Warner KE. The effects of the anti-smoking campaign on cigarette consumption. Am f Public Health 1977;67:645-50.

${ }^{26}$ Anonymous. Smoking and health in Canada. Staff Papers. Long Range Health Planning 1977;March:54.

${ }^{27}$ Herail RJ, Lovatt EA. Why anti-smoking advertising loses out. World Medicine 1979;14:15-7.

${ }^{28}$ Ramstrøm LM. New ideas in Sweden's tobacco labelling act. World Smoking and Health 1976;1:28.

${ }^{29}$ Delaney $\mathrm{B}$. Cigarette advertisements : time to end this dangerous hypocrisy. Campaign 5 December, 1980:28.

${ }^{30}$ Russell MAH, Jarvis M, Iyer R, Feyerabend C. Relation of nicotine yield of cigarettes to blood nicotine concentrations in smokers. $\mathrm{Br} \mathrm{Med} \mathcal{f}$ $1980 ; 280: 972-6$.

${ }^{31}$ US Surgeon General. The health consequences of smoking; the changing cigarette. Washington, DC: US Govt Print Off, 1981.

32 Kozlowski LT. Smokers, non-smokers, and low-tar smoke. Lancet 1981; i:508.

${ }^{33}$ Popham GT. Government and smoking: policy making and pressure groups. Policy and Politics $1981 ; 9: 331-47$.

${ }^{34}$ Friedman KM. Public policy and the smoking-health controversy; a comparative study. Lexington: Lexington Books, D C Heath, 1975.

${ }^{35}$ Muller M. Tobacco and the Third World: tomorrow's epidemic? London: War on Want, 1978:90-1.

(Accepted 21 Fanuary 1982)
The following is the text of a letter signed by the presidents of eight medical royal colleges, the secretary of the conference of medical royal colleges and their faculties in the United Kingdom, and the dean of the faculty of occupational medicine of the Royal College of Physicians of London, and sent to Mr Neil Macfarlane $M P$, the minister for sport, at the Department of the Environment on 14 December 1981.

We write to express our deep concern that any new voluntary agreement you may reach on this subject with the tobacco companies may prove too permissive and too long term. Indeed, from a medical point of view, only an end to all tobacco sponsorship would be completely satisfactory.

Our concern is, naturally, with the health of the people of this country. You will be aware that it is accepted by the medical profession, and by HM Government, that cigarette smoking is the single most important preventable cause of death and disability in the United Kingdom. The DHSS calculates that this is responsible for at least 50000 premature deaths each year from smoking-related diseases. The Royal College of Physicians of London $^{1}$ estimates that at least 50 million working days are lost annually through illness caused by smoking. In the young as well as in the old, smoking gives rise to much recurrent ill health.

No doubt these facts, among others, are responsible for the Government policy of discouraging smoking, especially in the young. In consequence, we are particularly concerned that sports sponsorship by tobacco interests will tend, in the minds of the young, to establish a paradoxical link between smoking on the one hand and, on the other, enjoyable participation in healthy sports. Moreover, tobacco sponsorship of sport is one method of circumventing the legal ban on the advertising of cigarettes on television and radio. A survey in $1980^{2}$ revealed that tobacco companies obtained, on BBC programmes alone, 190 hours of advertising through sports sponsorship in a period of six months. This compares strikingly with a total output of 160 hours of all forms of television broadcast each week; thus the tobacco companies achieved over a six months' period the equivalent of more than a whole week of broadcasting time. Earlier this year a single event sponsored by a tobacco company received 72 hours of television coverage. ${ }^{3}$ In addition, advertising in this way avoids the health warnings about smoking which are statutory in other forms of cigarette advertising.

Although it is not possible to demonstrate in advance the effects of an end to sports sponsorship by tobacco companies, the ban on all forms of tobacco advertising in Norway and Finland has been associated with an encouraging drop in cigarette smoking by children. The smoking rate in 14-year olds dropped from $19 \%(1973)$ to $8 \%(1979)$ in Finland, ${ }^{4}$ and from $16 \%$ (1975) to $13 \%(1980)$ for boys, and from $16.5 \%$ to $11 \%$ for girls in Norway $^{5}$ at a time when indeed it might otherwise have been expected to have risen. Of course, the ban on tobacco promotion was only part of an enlightened longer-term programme undertaken by the Norwegian and Finnish governments to discourage smoking, but no previous efforts had been so consistently successful.

We would like to record our great appreciation of the increased funding allocated by this Government to health education. It would be all the more regrettable if the efforts of health educators supported by Government were to continue being undermined by the contrary influence of the tobacco sponsorship of sport, with its tendency to glamorise, in the eyes of the young, an addictive and dangerous habit.

You will no doubt be aware that the World Health Assembly, of which HM Government is a member, has adopted the recommendation of the World Health Oganisation's Expert Committee on Smoking Control ${ }^{6}$ that one of the objectives of member governments' policies should be "the cessation of all forms of tobacco promotion."

We wish to emphasise that we welcome the sponsorship of sport by socially acceptable commercial interests and indeed, within financial constraints, by health education organisations.

We would briefly summarise our recommendations regarding any new agreement on the tobacco sponsorship of sport as follows:

(1) Ideally there should be a complete ban on tobacco sponsorship of sport. 